\title{
Renal Disease Burden in Sample Countries from Five Continents
}

\author{
Gamal Saadi, and Maggie S El Nahid* \\ Nephrology Division, Department of Internal Medicine, Cairo University, Giza, Egypt
}

*Corresponding author: El Nahid MS, Assistant Professor, Nephrology Division, Department of Internal Medicine, Nephrology division, Cairo University, 15B Radwan Ibn Tabib, Giza, Egypt, E-mail: Dr.migos@yahoo.com

Received: 07 Oct, 2020 | Accepted: 26 Oct, 2020 | Published: 30 Oct, 2020

Citation: Saadi G, El Nahid MS (2020) Renal Disease Burden in Sample Countries from Five Continents. Int J Nephrol Kidney Fail 6(4): dx.doi. org/10.16966/2380-5498.203

Copyright: (c) 2020 Saadi G, et al. This is an open-access article distributed under the terms of the Creative Commons Attribution License, which permits unrestricted use, distribution, and reproduction in any medium, provided the original author and source are credited.

\section{Abstract}

Background: Changes in population structure, aging pattern, and the increasing prevalence of diabetes and hypertension, are behind the increase in chronic kidney disease (CKD) prevalence and end stage renal disease (ESRD). Reliable and updated information on CKD patients and ESRD patient numbers and treatment modalities are essential to understand the real estimate of the renal disease burden in many countries. It was the aim of our study to investigate different regions of the world, as defined by world health organization (WHO): Africa, the Americas, South East Asia, Europe, East Mediterranean, and West Pacific regions, regarding many aspects of renal disease and renal replacement therapy.

Methods: We obtained data for 6 African countries, 4 Asian countries, 6 European countries, 2 Latin American one North American country. Data were collected regarding the prevalence of CKD, the main etiology of CKD, available forms of renal replacement therapy (RRT), hemodialysis (Hdx), Peritoneal Dialysis (PD) or renal transplantation (Tx), percent of health expenditure and the nephrology workforce in each country.

Results: The major etiology behind CKD; were hypertension and diabetes in most studied countries. Hdx is the main means of RRT more than PD. Lack of nephrology workforce may account for the inferior standard of therapy in many regions. A wide discrepancy exists, in the annual rates of renal transplantation among the studied countries.

Conclusion: The increasing prevalence of CKD must be met with judicious increase in the RRT services. Especially in the less fortunate world regions where dialysis (Dx) and renal Tx services come close to nil.

Keywords: Chronic kidney disease; Renal replacement therapy; Dialysis; Transplantation; Health expenditure; Nephrology workforce

\section{Introduction}

Chronic Kidney Disease (CKD) is reported with rising prevalence worldwide, and consequently that of End Stage Renal Disease (ESRD). The availability of Renal Replacement Therapy (RRT) including, dialysis and transplantation does not follow the same pattern of increase in many countries, unfortunately. In order to insure effective future planning by healthcare authorities, reliable and up-to-date information on CKD and ESRD patient numbers and treatment modalities are becoming basic requirements. An increasing number of national and international renal registries have provided valuable demographic and epidemiologic information on renal patients. In the coming study, we aim to obtain data from all regions of the world as defined by WHO: Africa, the Americas, South East Asia, Europe, East Mediterranean, and West Pacific regions [1]. Data will include the prevalence of CKD, the main etiology of CKD, available forms of RRT, Hemodialysis (Hdx), Peritoneal Dialysis (PD) or renal transplantation (Tx), percent of health expenditure and the nephrology workforce in each country.

\section{Methods}

We obtained data for 6 African countries (Egypt, Tunis, Nigeria, Congo, Senegal, South Africa), 4 Asian countries (United Arab Emirates, India, Iran, Turkey), 6 European countries (France, Bosnia, Macedonia, Italy, Russia, Georgia ), 2 Latin American (Brazil, Argentina), one North American, United States of America (USA) country.

Data about population, ethnic backgrounds, percent of health expenditure, Chronic Kidney Disease (CKD) prevalence and etiology, Renal Replacement Therapy (RRT), Hemodialysis (Hdx), Peritoneal Dialysis (PD), renal transplantation (Tx), living and deceased were gathered from 2018 to 2019 . The most recent data were included in our study.

We contacted a representative from each country and renal registry. We cited the annual report for national registry. We reported data from the most authoritative sources. Online databases were used when registries did not exist. Data were reviewed for accuracy during data entry and before analysis. Graphs and tables were created using Excel 2007 (Microsoft, Redmond, CA, USA). 


\section{Results}

Analysis of the collected data were classified according to the studied parameter as follows; percent of health expenditure, prevalence and etiology of CKD, prevalence of RRT, Dx modalities, Tx annual rates and living, deceased donors and nephrology workforce in each of the studied countries.

\section{Percent (\%) of health expenditure}

Countries were classified according to their percent of health expenditure to the total expenditure into the following;

- $\leq 5 \%$ of total expenditure: Egypt, United Arab Emirates (UAE), Tunis, India and Nigeria.

- 5-10\% of total expenditure: France, Bosnia, Brazil, Macedonia, Argentina, Iran and Turkey.

- $>10 \%$ of total expenditure: USA, South Africa and Georgia.

\section{CKD incidence, prevalence, etiology and ethnic peculiarity}

\section{CKD incidence and prevalence:}

The highest recorded CKD incidence was in Egypt, Georgia and Italy; (200, 200 and 300 per million of population (pmp) respectively). Other countries included Senegal (100 pmp), UAE (131 pmp), Argentina (110 pmp), USA (110 pmp), and France (163 pmp). The highest recorded CKD prevalence was in India, Brazil, USA, Congo and Nigeria; (262350, 133,900, 97,960, 110,000 and 84000) (Figure 1).

\section{CKD etiology:}

The major etiologies behind CKD were hypertension and diabetes in all. These were followed by chronic interstitial nephritis (CIN) in Egypt and glomerulonephritis (GN) in Georgia and Italy. The highest countries to record diabetes as a major cause of CKD were USA, Turkey and UAE (45\%, 41\%, 40\% respectively). The highest countries to record hypertension as a major cause of CKD were Italy, Senegal, Egypt and Brazil (50\%, 46\%, 35\% and 35\% respectively) (Figure 2).

CKD of unknown etiology contributed to the etiology of CKD by $>30 \%$ in UAE and India, $>20 \%$ in Egypt, Brazil, Tunis, Argentina, Georgia and Italy. It was the commonest cause of CKD in India and Georgia.

\section{According to ethnic peculiarity:}

Among countries and among the highest incidence countries, the major recorded ethnic group was Caucasians.

\section{Hemodialysis (Hdx), peritoneal dialysis (PD)}

Hdx is the main means of RRT more than PD. Some countries depend mainly on governmental Dialysis units (U.S.A, Egypt, France, UAE and Brazil), while others on private units (Tunis, India, Congo, Argentine and South Africa), (Figure 3, Table 1).

\section{Nephrology workforce}

Concerning the nephrology workforce, the ratio of nephrologists to population was as follows.

- >30 per million of population (pmp) Italy and Georgia.

- >20 pmp USA, Egypt, Argentina and France.

- $>10$ pmp UAE, Bosnia, Brazil, Tunis, Macedonia and Russia.

- 5 pmp Turkey.

- 1 pmp India, Nigeria, Congo, Iran, Senegal and South Africa.
Transplant $(\mathrm{Tx})$ rate/year, percentage of renal replacement therapy (RRT), private $v s$. public units

The yearly Tx rate differed from one country to the other with great variability ranging from $0 \mathrm{Tx}$ to thousands Tx yearly. USA is on top of the list with an annual rate of 18,000 Tx and countries like Congo and Senegal have no Tx activity at all (Figure 4).

Countries annual $\mathrm{Tx}$ were classified as follows:

- $>5000$ Tx/year India and Brazil.

- >1000 Tx/year Iran, France, Turkey, Italy, Egypt and Argentina.

- $>500 \mathrm{Tx} /$ year Russia.

- $>100 \mathrm{Tx} /$ year Tunis, South Africa.

- 50-100 Tx /year Nigeria.

- $<50 \mathrm{Tx} /$ year Georgia, Macedonia, UAE and Bosnia.

Concerning living and deceased donors, Countries can be classified as follows:

- Only living donation: Egypt, UAE, Nigeria and Georgia.

- More living than deceased: Bosnia, Tunis, India, Macedonia and Turkey.

- More deceased than living: USA, France, Brazil, Argentina, Iran, South Africa, Italy and Russia.

\section{Discussion}

\section{Health expenditure}

Our study examined the percent of health care expenditure from total expenditure. Some countries spent $5 \%$ or less on health care. These include Egypt, UAE, Tunis, India and Nigeria. Other countries spent from 5 to $10 \%$ on health care, namely, France, Bosnia, Brazil, Macedonia, Argentina, Iran and Turkey. USA, South Africa and Georgia spent over $10 \%$ on health care.

Across the globe, there is a wide variation in health care expenditure, ranging on average from 3-12\% of Gross Domestic Product (GDP). Income (per capita GDP) has been identified as the major factor behind these differences [2].

Jakovljevic M, et al. stated that the USA is the largest health care market, allocating around 15\% of GDP for health care. Brazil, Russia, India, China and South Africa made greater investments in health care [3]. A study by Farag M, et al. found that a $1 \%$ increase in GDP was associated with $0.66 \%$ increase in government health expenditure in low-income countries and $0.96 \%$ increase in middle-income countries [4]. A possible explanation to our results can be driven from the fact that health expenditures are relatively larger in developed countries compared to developing countries [4].

Gökhan ABA, et al. conducted a study to determine the relationship between health expenditures and socioeconomic/demographic factors. 180 countries were included in the sample. Examination of countries based on income groups, showed that there was a 10 -fold difference between the highest and lowest values. Higher income group countries showed higher public and per person health expenditure rates. The total health expenditure of high income level countries versus low income level countries was $7.86 \%$ and $6.21 \%$ respectively. In terms of total health expenditures, the lowest rate belonged to South East Asia and the highest rate was in Europe [5]. In our study, the difference was even bigger between high and low income countries, ranging from less than $5 \%$ to more than $10 \%$. 


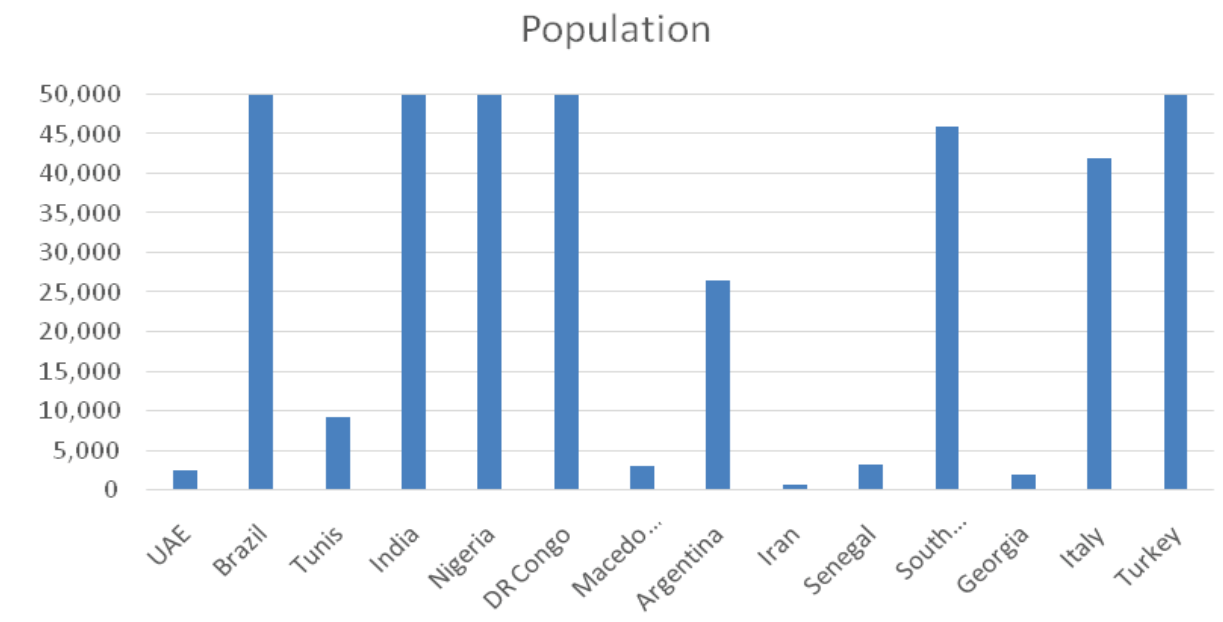

Figure 1: CKD population in different countries.

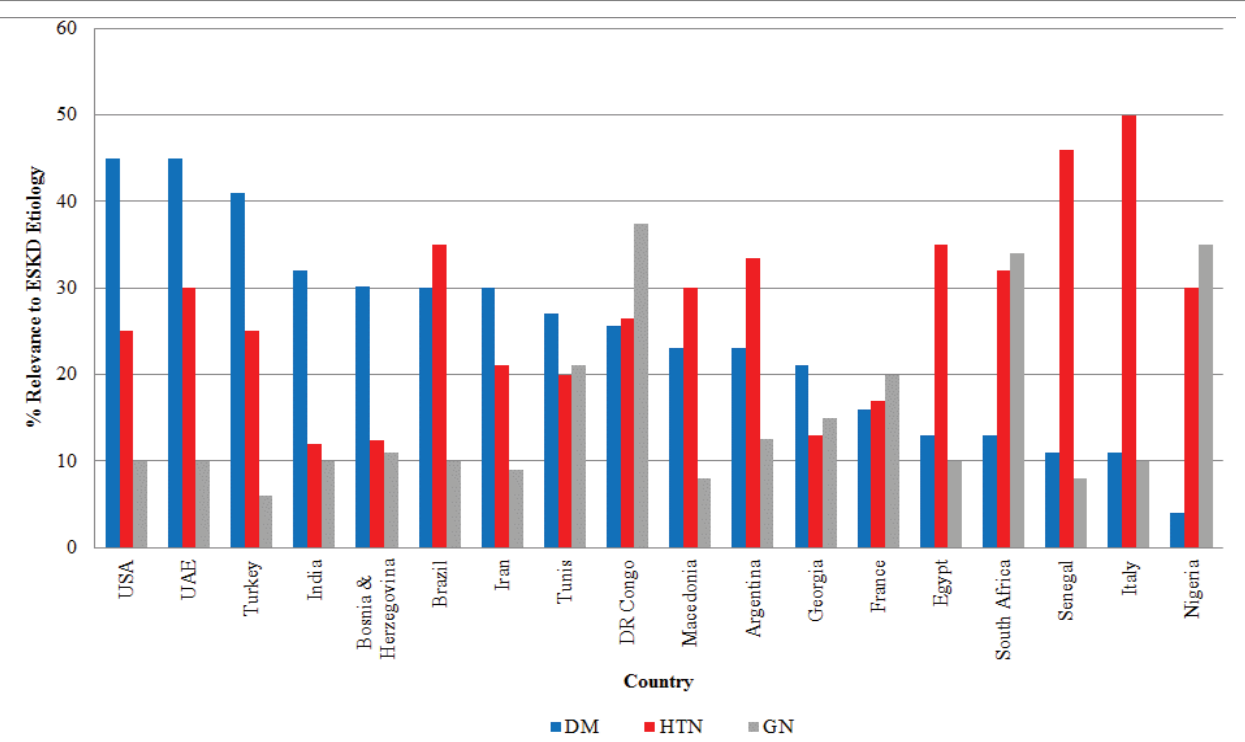

Figure 2: Etiology of CKD in different countries.

The major finding in the study of Gökhan ABA, et al. was that there was a negative correlation between total health expenditure and growth rate of population [5]. A finding that is also evident in our study, the heavily populated countries as India, Nigeria and Egypt had the lowest percent of health care expenditure. Overpopulation seems to consume the country's resources. This leads to uneven distribution of the GDP, which is mostly driven to satisfy basic needs as food, housing and sanitation. This ultimately affects health care share of the GDP [5].

However it is, worth noting that the major discrepancies between countries' health expenditure rates cannot be solely related to the socioeconomic and demographic features alone. Health policies within each country seem to have an impact on health care systems in general. It should be emphasized that increasing budget for health expenditures will, in turn, will lead to an acceleration in economic growth [6].

\section{Chronic kidney disease}

Data were collected to examine the CKD prevalence, the major etiologic factors and the geographic and ethnic distribution among the studied countries. The highest recorded CKD incidence was in Egypt, Georgia and Italy. The highest recorded CKD prevalence was in India, Brazil, USA, Congo and Nigeria.

The major etiologies behind CKD were hypertension and diabetes in all of the studied countries, followed by Chronic Interstitial Nephritis in Egypt and Glomerulonephritis in Georgia and Italy.

CKD of unknown etiology contributed to the etiology of CKD by $>30 \%$ in UAE and India, $>20 \%$ in Egypt, Brazil, Tunis, Argentina, Georgia and Italy. It was the commonest cause of GN in India and Georgia. Among countries and among the highest incidence countries, the major ethnic group was Caucasians. 


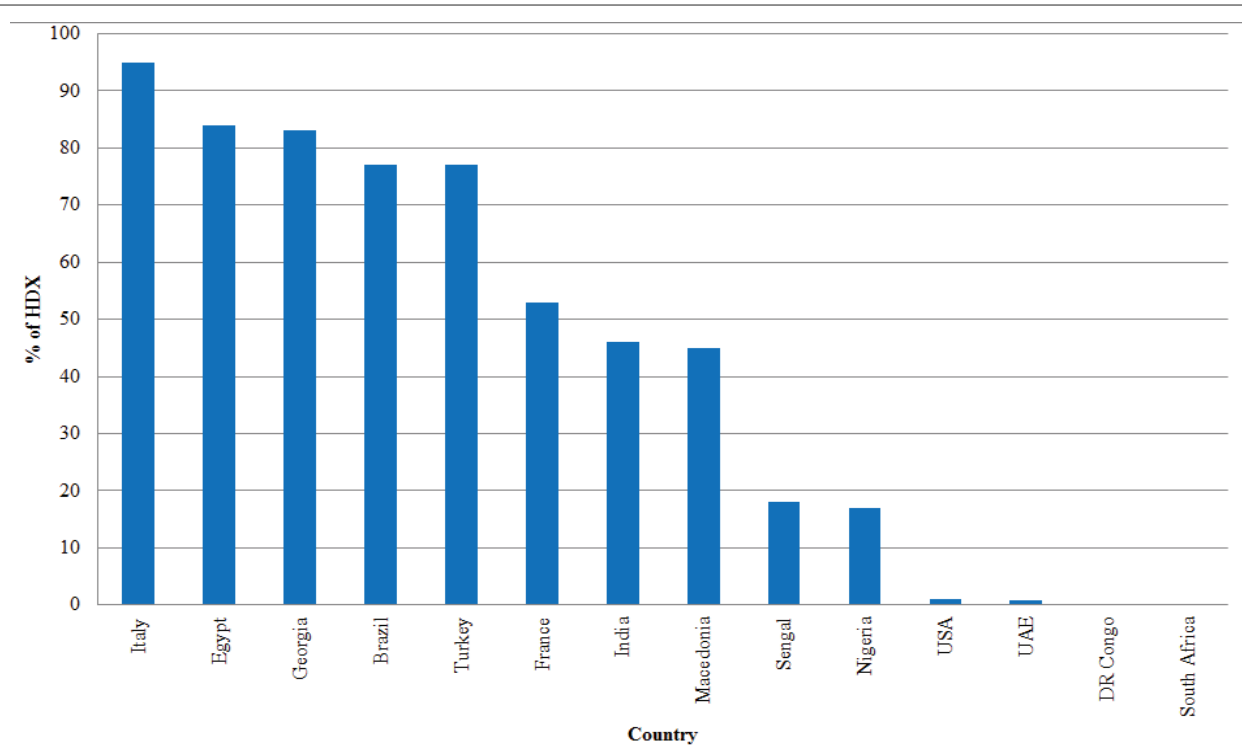

Figure 3: Percent of hemodialysis of recruited CKD patients.

Table 1: Percentage of HDx in the recorded CKD population.

\begin{tabular}{|l|c|l|c|}
\hline \multicolumn{1}{|c|}{ Country } & Percentage & \multicolumn{1}{c|}{ Country } & Percentage \\
\hline Egypt & 84 & Brazil & 77 \\
\hline USA & 1 & Tunis & NA \\
\hline France & 53 & India & 46 \\
\hline UAE & 0.8 & Nigeria & 17 \\
\hline Bosnia & NA & Congo & 0.2 \\
\hline Macedonia & 45 & Georgia & 83 \\
\hline Argentina & NA & Italy & 95 \\
\hline Iran & NA & Russia & NA \\
\hline Senegal & 18 & Turkey & 77 \\
\hline South Africa & 0.1 & & \\
\hline
\end{tabular}

In the last decade, widespread implementation of renal function measurements and GFR estimation have increased our ability to detect early renal disease and as well to categorize stages of CKD and determine prognosis [7].

The data from the American National Health and Nutrition Examination Survey confirmed the increasing prevalence of CKD worldwide. USA, Canada, Europe and Australia had higher rates of CKD prevalence compared to many developing countries. Reported estimates for prevalence rate for example are Saudi Arabia 5.7\% and Sub Saharan Africa from 3\%-19\% [8].

Mills KT, et al. stated that the global prevalence of CKD in 2010 was 225.7 million men and 271.8 million women, 48.3 million men and 61.7 million women in high-income countries, and 177.4 million men and 210.1 million women in low- and middle-income countries [9]. Hill NR, et al. covering 112 populations concluded that the global prevalence of CKD was about $13.4 \%$ [10].

Examination of the CKD prevalence by geographical grouping showed the following results among countries: Senegal, South Africa and Congo (8.6\%), India (13\%), China (4.3\%), Japan (3.3\%), Australia (3.3\%), USA (3.8\%), Canada (12.5\%), Europe (18.38\%), Italy (6.1\%), Georgia (16.8\%), Bosnia (10.4\%), Macedonia (6.9\%) Argentina (8.7\%), France (2.5\%) and Russia (8.1\%) [11].
The geographical stratification showed that high prevalence was related to diet, high BMI and the presence of comorbidities as hypertension. This possibly explains the higher prevalence in developed countries versus developing. And also points out to a potential increase in prevalence of CKD in developing countries with industrialization of the diet and increasing elderly population [12]. Wherever there is increased prevalence of diabetes, hypertension, obesity and aging, there is a subsequent increase in CKD. This is the basis of the observed regional variation in CKD prevalence.

In developing countries glomerular and tubule-interstitial diseases add to CKD burden. Higher exposure to repeated infections, nephrotoxic drugs, occupational exposure and herbal medicines are all contributing factors [13].

In agreement with these findings, our study showed that the highest prevalence of CKD was found in both developed (Italy) and developing (Egypt) countries. Our results also stated that the major etiologic factors behind this high prevalence were diabetes, hypertension, tubule-interstitial disease and glomerulonephritis.

In patients undergoing RRT, diabetes was the commonest cause in Europe and Central Asia, hypertension in Brazil, and in Egypt and glomerulonephritis in East Sub-Saharan Africa and South Asia [14]. Worth noting is that although the prevalence of hypertension decreased by $2.6 \%$ in high-income countries, it increased by $7.7 \%$ in low-and middle-income countries [15]. The West Pacific region had the highest prevalence of diabetes of $8.3 \%$. These increases are closely related to increasing life span, changes in diet and obesity [16].

Highest prevalence of diabetes is seen in Kuwait (21.1\%), Lebanon (20.2\%), Saudi Arabia (20.0\%), Bahrain (19.9\%) and United Arabian Emirates (19.2\%). The North America/Caribbean region comes second in line with a 10.7\%, Europe a 6.7\%, Central America and East Asia 9.2\% (16). Africa had the lowest rate of 4.5\%. However, Africa had a high rate of undiagnosed cases of diabetes around 78\% [16].

Concerning the contribution of GN to the etiology of CKD, in our study, especially in Egypt, there is a close links to chronic infections, for example HBV, HCV and membrano-proliferative GN. Variations between countries in infection rates will contribute to differences in 


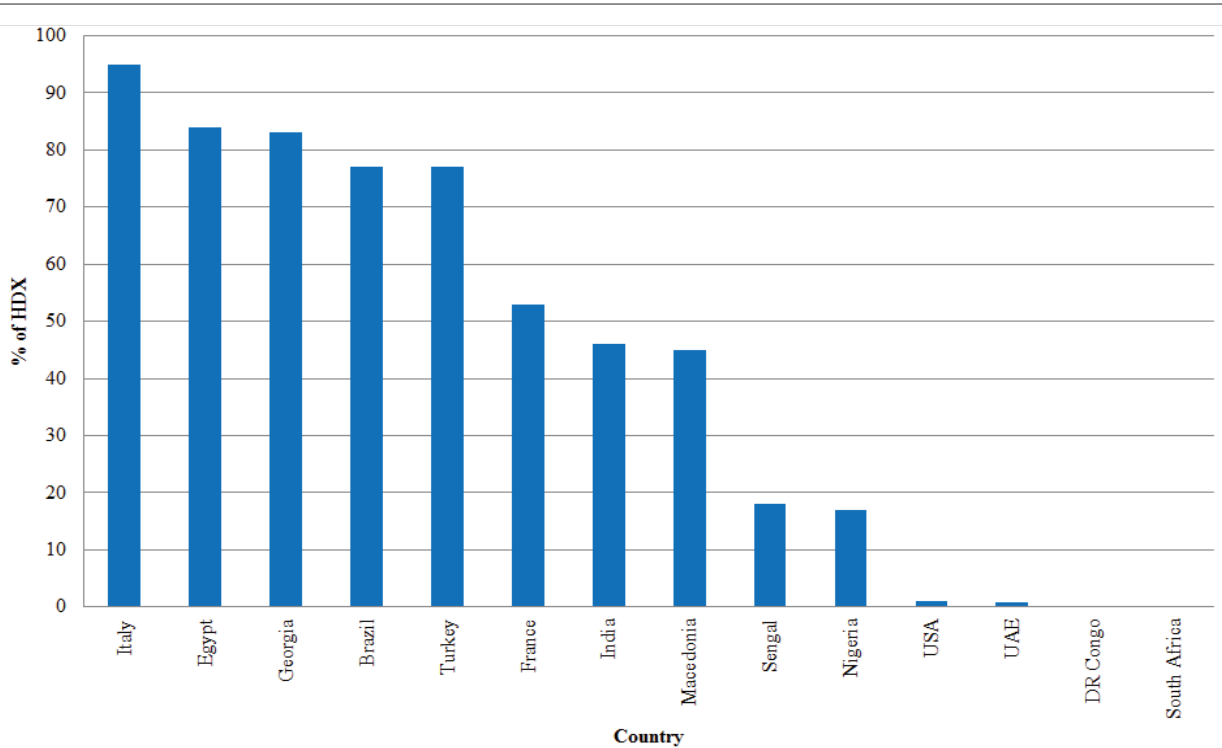

Figure 4: Percent of transplantation of recruited CKD patients.

incidence rates. A large cohort study reported decreases in eGFR and increases in ESRD in HCV-infected individuals compared to controls [17]. Egypt is known to bare a large HCV prevalence, and is perhaps the most affected nation by this infection [18]. This fact is supported by the high incidence of GN in Egypt in our study.

It is worth noting, that our study draws attention to an important area in the study of CKD etiology, namely, CKD of unknown etiology. This entity contributed to the etiology of CKD by $>30 \%$ in UAE and India, $>20 \%$ in Egypt, Brazil, Tunis, Argentina, Georgia and Italy. It comprised the first cause of CKD in India and Georgia.

The increase in the prevalence of a CKD of unknown etiology $(\mathrm{CKDu})$ is evident in many countries: Nicaragua, El Salvador, Costa Rica, Sri Lanka, Egypt and India [19]. In a study of patients with CKD in Nigeria, the etiology was undetermined in $62 \%$ [20]. CKDu has its own unique characteristics and is a rising health concern [21].

A study examining CKD prevalence in five communities with different economic activities and at different altitudes, found that working in sugarcane or cotton factories increased the risk of CKD. No increased risk was seen in higher altitudes. The authors concluded that long hours of work in hot climates, may expose to dehydration and chronic decreases in GFR. The study also reported a relation to the use of pesticides in agriculture [22]. In Egypt, another study showed an association between the CKD and drinking unclean water [23]. The racial disparity is also evident in the difference in prevalence of hypertension among African Americans compared to Caucasians. Economic and social factors also contribute to these disparities [24].

\section{Dialysis}

Our study examined the dialysis modalities in the studied countries. Hdx was the main means of RRT, more than PD in all of the studied countries. Some countries depended mainly on governmental Dialysis units (USA, Egypt, France, UAE and Brazil), while others on private units (Tunis, India, Congo, Argentine and South Africa). Of the dialysis patients worldwide, $89 \%$ were treated by $\mathrm{Hdx}$ and $11 \%$ were undergoing peritoneal dialysis (PD) [25].
In Europe, Central Asia, Middle East and North Africa region the majority of patients undergo hemodialysis. In Latin America and the Caribbean, hemodialysis is less frequently used. On the other hand, PD is the main mode of dialysis in Mexico, El Salvador, Guatemala, Dominican Republic and Nicaragua. This is largely because PD is less expensive and with equal outcomes, compared to $\mathrm{Hdx}$ [26]. However, this is not always the case because of the expense of importing PD supplies [27].

In our study, some countries depend mainly on governmental Dialysis units, like the USA, Egypt, France, UAE and Brazil, others on private units like Tunis, India, Congo, Argentine and South Africa.

Choices between a public or private unit may be limited by the fact that public units are included in government health care system, therefore, the dialysis service is offered at a much lower price than the private units. Service may or may not be similar to private units but economic factors can influence the choice between a public or private unit [28].

Of interest is the wide range of variability in Hdx service among the studied countries. No recorded data were found for Tunis, Bosnia and Russia. Some figures were as low as $0.1 \%$ of total CK population as in South Africa, in contrast to $95 \%$ in Italy. Hdx service was $<1 \%$ in UAE, Congo and South Africa, $<50 \%$ in India, Nigeria, Macedonia and Senegal, $>50 \%$ in Egypt, France, Brazil, Georgia, Italy and Turkey.

North America and Pacific Asian regions had the highest prevalence for maintenance dialysis. Sub-Saharan Africa and South and Central Asia had the lowest estimates [29]. As evident in our study, the percent of dialysis service in South Africa was only $0.1 \%$.

In Africa and South Asia countries, there's an untreated burden of ESRD. These countries, mostly lack resources for maintenance dialysis. The inadequacy of dialysis often affects sections of society already at risk of CKD, like the poor or the aging [30].

A study of $>2000$ patients with ESRD in South Africa, revealed that failure to provide dialysis service was related to transportation difficulties, economic and social factors. This indicates limited 
availability of RRT rather than a decrease of disease burden. Over the last two decades, however, Central Latin America and Eastern Europe showed significant progress in increasing dialysis services [30].

There is an evident worldwide discrepancy between the prevalence of ESRD and RRT services. An outstanding example is the high prevalence of diabetes in India and Egypt compared to that of the USA. However, the provision of RRT in the USA is incomparable to that provided in these two countries [14].

The Eastern European and Central Asian countries had lower rates of RRT compared with Latin America countries. In Brazil, the government aimed at reimbursing RRT and a greater dependence on PD [14].

\section{Transplantation}

In our study we aimed to explore the extent of contribution of renal transplantation to the overall RRT in the studied countries. There was a wide range of variability in the annual rates of transplantation. Transplantation rates were nil in some regions in Africa, namely Congo and Senegal. USA was on top of the list with an annual rate of $18,000 \mathrm{Tx}$. Some countries allow only living donor transplantation, others permit living and deceased.

Several other studies addressed the same topic, with similar results as ours. According to a study by Horvat LD, et al, 2009, around 27,000 living kidney donor transplants occur worldwide each year, with $39 \%$ of which are derived from living donors, more in richer nations than poorer ones. Transplant rates of are restricted to USA, Europe and Australia [31].

The greatest numbers of living kidney donor transplants are performed in the USA, Brazil, Iran, Mexico, Japan and India. Less than 10 living kidney donor transplants a year were performed in Croatia, Cuba, Finland, Iceland and Uruguay. Luxembourg and Slovenia are the only countries where no living kidney donations were performed in recent years [32]. However, annual transplantation rates of France, Turkey, Italy, Egypt, Argentina, Tunis, South Africa, Nigeria, UAE and Bosnia, were not included in his study.

Several reasons lie behind the wide differences, among nations in the rates of transplantation. Economic factors play a major role. Nation's or patient's wealth determines the likelihood of receiving a transplant [33]. Almost all countries banned commercialism, declaring it illegal to buy or sell organs. However, this has not prevented such practice in some regions as China and Pakistan [34].

Our study revealed the pattern of transplantation worldwide. Some countries only performed living transplantation, namely Egypt, UAE, Nigeria and Georgia. Some performed more living than deceased, namely; Bosnia, Tunis, India, Macedonia and Turkey. Others performed more deceased than living like USA, France, Brazil, Argentina, Iran, South Africa, Italy and Russia.

Similarly, Horvat LD, et al. in 2009 stated that there were no deceased donor kidney transplants in Algeria, Dominican Republic, Egypt, Iceland, Jordan, Morocco, and Nicaragua. Rates increased steadily in Algeria, Brazil, Canada, Mexico, USA, and Latin America. Some European countries have low rates of living donations as, Italy, Czech Republic, Belgium, France, Finland, Hungary, Spain and Poland. The United Kingdom, Hungary, the Netherlands and Portugal show increasing rates of transplantation [31]. Rates in Austria, France, Sweden, and Turkey doubled in the past few years. Similarly, in Saudi Arabia, Iran, Jordan, Morocco, and Tunisia. Significant increases were also reported in Australia, New Zealand, Japan, Malaysia, and
Singapore. Interestingly, the increases also included unrelated kidney donation [31].

Paired exchange gained popularity in some countries like the United States, the Netherlands, Switzerland and Korea [35]. National legislation of deceased donation, due to socio-political issues or lack of legal framework, affects the total rate of annual transplantation in many countries [36]. The newer concepts of donation after cardiac death' instead of "brain death", influenced donation numbers. Facilities like rapid cooling and efficient organ retrieval, available in some countries, are major determinants of the annual transplantation rate [37].

The situation in China is slightly different. Many discrepancies in the reported annual transplant numbers. Trey T, et al, 2016 expressed that it is not possible to include China as a legitimate partner in the international transplant community because of unauthorized organ procurement from prisoners [38].

Unfortunately, countries like China and India still lack credible national registry. Reliable information, proper data recording and analysis are crucial for evaluation of transplantation status in any country [31].

Efforts to enhance living donation, as well as, organizing well managed deceased organ donation programs, are now essential to be able to meet the growing needs for organ transplantation.

\section{Recommendations}

The RRT in developing countries face many challenges. Efforts should be made to minimize the occurrence of ESRD. In this context, providing adequate and effective RRT. The designation of renal disease as an important non-communicable disease at the United Nations High Level Meeting was an important initiative [39]. In developing countries; implementing sound organ donation systems, affordable immunosuppressive drugs; legislation of deceased donation, prohibition of organ trafficking and improving professional standards of medical practice are all needed to complement renal transplantation programs.

The International Federation of Kidney Foundations (IFKF) has played a major role to advocate for kidney disease awareness, to introduce educational services to prevent kidney disease occurrence or progression. They also helped to implement a global network for national and international registries for the incidence, prevalence and risk factors of CKD. The IFKF called for implementing international screening guidelines and sharing best practice information. They highlighted the importance of tailoring management protocols according to national resources and facilities. Working on nonmedical frontiers as well, they urged evaluating government and private health services and introducing recommendations to policy makers for adequate health services to CKD patients. Special focus was given to establishment of health services to CKD patients in regions lacking them and building equal access to health care to meet the IFKF mission. Fund raising to sustain multiple IFKF efforts was mandatory at all stages.

Our study helped throw light on some of the management problems of CKD and ESRD. Problems that mainly reflect inadequacy of health care funding, inadequacy of RRT provision and inequity of distribution of RRT services among nations. In light of the growing CKD population, these problems will expand by time unless measures are taken to halt their progress. Therefore, our study serves to raise awareness to the importance of joined efforts of governments, health care givers, private sectors and societies, to meet the expanding demand of CKD and ESRD. 


\section{List of Contributors}

Abdou Niang (Senegal), Achour Abdellatif (Tunis), Arogundade Fatiu (Nigeria), Charles Swanepoel (South Africa), Elena Zakharova (Russian Federation), FP Schena (Italy), Goce Spasovski Olivera Stojceva Taneva (Macedonia), Halima Resic (Bosnia and Herzegovina), Irma Tchokhonelidze (Georgia), K Kalantar-Zadeh (USA), Latha A Kumaraswami (India), Maria Bianchi (Argentina), Maurice Laville (France), Miguel C Riella (Brazil), Mitra Mahdavi-Mazdeh (Iran), Mona Alrukhaimi (UAE), Sumaili Kiswaya (DR Congo), Timur Erk (Turkey).

\section{References}

1. Nugent RA, Fathima SF, Feigl AB, Chyung D (2011) The Burden of Chronic Kidney Disease on Developing Nations: A 21 $1^{\text {st }}$ Century Challenge in Global Health. Nephron Clin Pract 118: c269-c277.

2. Schieber GJ (1990) Health expenditures in major industrialized countries, 1960-87. Health Care Financ Rev 11: 159-167.

3. Jakovljevic M, Getzen TE (2016) Growth of Global Health Spending Share in Low and Middle Income Countries. Front Pharmacol 7: 21.

4. Farag M, Nandakumar AK, Wallack SS, Gaumer G, Hodgkin D (2009) Does funding from donors displace government spending for health in developing countries? Health Aff (Millwood) 28: 1045-1055.

5. Gökhan ABA, Metin ATEŞ (2016) The relationship between health expenditure and socioeconomic/demographic indicators: an international comparison. Int J Health Sci Manag 2: 113-118.

6. World Bank (2014) World Bank list of economies. Washington, DC, USA

7. Lopez-Giacoman S, Madero M (2015) Biomarkers in chronic kidney disease, from kidney function to kidney damage. World J Nephrol 4: 57-73.

8. Coresh J, Selvin E, Stevens LA, Manzi J, Kusek JW, et al. (2007) Prevalence of Chronic Kidney Disease in the United States. JAMA 298: 2038-2047.

9. Mills KT, Xu Y, Zhang W, Bundy JD, Chen CS, et al. (2015) A systematic analysis of worldwide population-based data on the global burden of chronic kidney disease in 2010. Kidney Int 88: 950-957.

10. Hill NR, Fatoba ST, Oke JL, Hirst JA, O'Callaghan CA, et al. (2016) Global Prevalence of Chronic Kidney Disease-A Systematic Review and Meta-Analysis. PLoS One 11: e0158765.

11. Bikbov B, Purcell CA, Levey AS, Smith M, Abdoli A, et al. (2020) Global, regional, and national burden of chronic kidney disease, 1990-2017: a systematic analysis for the Global Burden of Disease Study 2017. Lancet 395: 709-733.

12. Boutayeb A (2006) The double burden of communicable and noncommunicable diseases in developing countries. Trans R Soc Trop Med Hyg 100: 191-199.

13. Prevend Study. Assessing the Impact of Microalbuminuria. The Second Survey 2005. Gröningen (NL): Trial Co-ordination Center of the University Medical Center Groningen.

14. Anand S, Bitton A, Gaziano T (2013) The Gap between Estimated Incidence of End-Stage Renal Disease and Use of Therapy. PLoS One 8: e72860.

15. Mills KT, Bundy JD, Kelly TN, Reed JE, Kearney PM, et al. (2016) Global Disparities of Hypertension Prevalence and Control: A Systematic Analysis of Population-based Studies from 90 Countries. Circulation 134: 441-450.
16. Spanakis EK, Golden SH (2013) Race/Ethnic Difference in Diabetes and Diabetic Complications. Curr Diab Rep 13: 814-823.

17. Azmi AN, Tan SS, Mohamed R (2015) Hepatitis C and kidney disease: An overview and approach to management. World J Hepatol 7: 7892.

18. Mohamoud YA, Mumtaz GR, Riome S, Miller D, Abu-Raddad LJ (2013) The epidemiology of hepatitis C virus in Egypt: a systematic review and data synthesis. BMC Infect Dis 13: 288.

19. World Health Organization (2008) Chronic Kidney Disease of Unknown Aetiology (CKDu). A New Threat to Health, WHO Country Office for Sri Lanka, Colombo, Sri Lanka.

20. Jayatilake N, Mendis S, Maheepala P, Mehta FR, CKDu National Research Project Team (2013) Chronic kidney disease of uncertain aetiology: prevalence and causative factors in a developing country. BMC Nephrol 14: 180.

21. Redmon JH, Elledge MF, Womack DS, Wickremasinghe R, Wanigasuriya KP, et al. (2014) Additional perspectives on chronic kidney disease of unknown aetiology (CKDu) in Sri Lanka--lessons learned from the WHO CKDu population prevalence study. BMC Nephrol 15: 125.

22. Chronic kidney disease in rural communities (2014) MEDICC Rev 16.

23. Almaguer M, Herrera R, Orantes CM (2014) Chronic kidney disease of unknown etiology in agricultural communities. MEDICC Rev 16: 9-15.

24. Lackland DT (2014) Racial Differences in Hypertension: Implications for High Blood Pressure Management. Am J Med Sci 348: 135-138.

25. Grassmann A, Gioberge S, Moeller S, Brown G (2005) ESRD patients in 2004: global overview of patient numbers, treatment modalities and associated trends. Nephrol Dial Transplant 20: 2587-2593.

26. Riella MC, Locatelli AJ (2007) History of peritoneal dialysis in Latin America. Perit Dial Int 27: 322-327.

27. Finkelstein FO, Abu-Aisha H, Najafi I, Lo WK, Abraham G, et al. (2009) Peritoneal dialysis in the developing world: recommendations from a symposium at the ISPD meeting 2008. Perit Dial Int 29: 618-622.

28. Gitto L, Santoro D, Sobbrio G (2006) Choice of dialysis treatment and type of medical unit (private vs. public): application of a recursive bivariate probit. Health Econ 15: 1251-1256.

29. Stewart JH, McCredie MRE, Williams SM, Jager KJ, Trpeski L, et al. (2007) Trends in incidence of treated end-stage renal disease, overall and by primary renal disease, in persons aged 20-64 years in Europe, Canada and the Asia-Pacific region, 1998-2002. Nephrology (Carlton) 12: 520-527.

30. Thomas B, Wulf S, Bikbov B, Perico N, Cortinovis M, et al. (2015) Maintenance Dialysis throughout the World in Years 1990 and 2010. J Am Soc Nephrol 26: 2621-2633.

31. Horvat LD, Shariff SZ, Garg AX, Donor Nephrectomy Outcomes Research (DONOR) Network (2009) Global trends in the rates of living kidney donation. Kidney Int 75: 1088-1098.

32. World Health Organization (WHO). Global Knowledge Base on Transplantation (GKT). Geneva, Switzerland.

33. Shimazono $Y$ (2007) The state of the international organ trade: a provisional picture based on integration of available information. Bull World Health Organ 85: 955-962.

34. World Health Organization (WHO) WHO Guiding Principles on Human Cell, Tissue and Organ Transplantation. Geneva, Switzerland. 
35. de Klerk M, Haase-Kromwijk BJJM, Witvliet M, Claas FHJ, Weimar W (2007) Favourable results of the first 2 years of the Dutch paired, living donor, kidney exchange programme. Ned Tijdschr Geneeskd 151: 130-133.

36. Abadie A, Gay S (2006) The impact of presumed consent legislation on cadaveric organ donation: A cross-country study. J Health Econ 5: 599-620.

37. Bernat JL, D'Alessandro AM, Port FK, Bleck TP, Heard SO, et al. (2006) Report of a National Conference on Donation after cardiac death. Am J Transplant 6: 281-291.

38. Trey T, Sharif A, Schwarz A, Singh MF, Lavee J (2016) Transplant Medicine in China: Need for Transparency and International Scrutiny Remains. Am J Transplant 16: 3115-3120.

39. Garcia-Garcia G, Harden P, Chapman J (2012) The global role of kidney transplantation for the world kidney day steering committee 2012. Int J Organ Transplant Med 3: 1-8. 